\title{
The effect of dietary benzoic acid concentration on nitrogen utilisation, manure ammonia and odour emissions in finisher pigs
}

\author{
D P Murphy, J V O'Doherty, K M Pierce, T M Boland, J J Callan, M B Lynch \\ University College Dublin, Dublin, Ireland \\ Email: diarmuid.murphy@ucdconnect.ie
}

Introduction Pig production is associated with ammonia and odour emissions causing nuisance, environmental and public concerns. Recent studies have suggested that it is possible to change the production of ammonia and odour by changing the conditions in the slurry through dietary interventions (Lynch et al., 2008). Slurry pH is one of the most significant factors influencing ammonia emission, ammonia volatilisation increasing with an increasing manure pH. Buhler et al., (2006) demonstrated that dietary benzoic acid significantly lowered urinary $\mathrm{pH}$ in grower and finisher pigs. Therefore, the objective of the following study was to investigate the effects of benzoic acid concentration as a feed additive on nitrogen utilisation, manure ammonia and odour emissions in finishing pigs.

Materials and methods The experiment was designed as a complete randomised design comprising of four dietary treatments: (T1) $0 \mathrm{~g} / \mathrm{kg}$ benzoic acid, (T2) $10 \mathrm{~g} / \mathrm{kg}$ benzoic acid, (T3) $20 \mathrm{~g} / \mathrm{kg}$ benzoic acid, (T4) $30 \mathrm{~g} / \mathrm{kg}$ benzoic acid. Sixteen boars were selected according to a uniform weight $(64 \pm 1.5 \mathrm{~kg})$, and allocated to one of four dietary treatments as described above $(n=4)$. Pigs were transferred to individual metabolism crates to facilitate studies on nitrogen utilisation, manure ammonia and odour emissions. The collection period was subdivided into three parts; 1) $\mathrm{NH}_{3}$ emission (days 1 to 2); 2) odour emission (days 3 to 5) and 3) $\mathrm{N}$ utilisation (days 6 to 10). Ammonia emission from the manure was measured over a $240 \mathrm{~h}$ period, in a laboratory scale set-up (O'Shea et al., 2009). Ammonia production (mg) from manure was compared between the different dietary treatments using the quantity volatilised from 0 to $240 \mathrm{~h} / \mathrm{g}$ of $\mathrm{N}$ intake. Air samples, used to measure odour concentration were collected directly above the storage container in 201 Nalophan sampling bags and analysed for odour concentration using an Ecoma T08 dynamic olfactometer as described by Lynch et al., (2008).For the $\mathrm{N}$ utilisation study, urine volume was recorded daily and a 50-ml sample was collected and frozen for laboratory analysis. Total faeces weight was also recorded daily and all faeces were oven dried at $100^{\circ} \mathrm{C}$. A sample of fresh faeces was collected twice daily for $\mathrm{N}$ analysis. Experimental data were analysed as a complete randomised design using the GLM procedure of the SAS Institute (1985). The statistical model included the linear and quadratic effects of benzoic acid.

Results There was a significant linear decrease $(\mathrm{P}<0.05)$ in urinary nitrogen excretion and total nitrogen excretion as the level of benzoic acid inclusion increased in the diet. Manure ammonia emissions were linearly reduced by 30,41 and $72 \%$ as the dietary benzoic acid concentration increased. However, there was no effect of benzoic acid on odour concentration across all treatments.

Discussion In the current study, manure ammonia emissions were decreased linearly with increasing dietary benzoic acid. This may reflect the linear decrease in manure $\mathrm{pH}$ which was also demonstrated (Table 1). In addition, the current study reported no effect on odour emissions despite the significant reduction in manure ammonia emission as benzoic acid increased. This is in agreement with the findings of Lynch et al., (2008) who reported no correlation between manure ammonia and odour emissions from finisher pigs.

Table 1 Effect of dietary benzoic acid inclusion level on manure composition and nitrogen balance (LSM \pm s.e.m.)

\begin{tabular}{|c|c|c|c|c|c|c|c|}
\hline \multirow[t]{2}{*}{ Treatment } & \multicolumn{5}{|c|}{ Benzoic acid concentration $\mathrm{g} / \mathrm{kg}$} & \multicolumn{2}{|c|}{ Significance } \\
\hline & 0 & 10 & 20 & 30 & s.e.m & Linear & Quadratic \\
\hline Urinary $\mathrm{N}$ excretion (g/day) & 25.3 & 21.6 & 23.5 & 19.1 & 1.6 & $*$ & ns \\
\hline Total N excretion (g/day) & 35.5 & 33.6 & 34.6 & 30.3 & 1.9 & $*$ & ns \\
\hline $\mathrm{pH} \mathrm{0-240} \mathrm{h}$ & 8.96 & 8.46 & 8.08 & 7.40 & 0.33 & $* *$ & ns \\
\hline Ammonia (mg/g N intake) $0-240 \mathrm{~h}$ & 141.3 & 99.1 & 83.8 & 40.4 & 12.0 & $* * *$ & ns \\
\hline Odour $\mathrm{Ou}_{\mathrm{E}} / \mathrm{m}^{3}(72 \mathrm{~h})$ & 22090 & 27620 & 35462 & 32627 & 5709 & $\mathrm{~ns}$ & ns \\
\hline
\end{tabular}

Linear $=$ linear response to dietary benzoic acid, quadratic $=$ quadratic response to benzoic acid. $* \mathrm{P}<0.05, * * \mathrm{P}<0.01$, $* * * \mathrm{P}<0.001, \mathrm{~ns}=$ non significant $(\mathrm{P}>0.05)$.

Conclusion Dietary inclusion of benzoic acid linearly reduced urinary nitrogen and total nitrogen excretion and furthermore linearly reduced manure ammonia emissions. Odour emissions were not influenced by benzoic acid inclusion in the current study.

Acknowledgements The authors gratefully acknowledge funding from the Department of Agriculture, Fisheries \& Food.

\section{References}

Buhler, K., Wenk, C., Broz, J., and Gobert, S. 2006. Archives of Animal Nutrition. 60, 382-389.

Lynch, M. B., O’Shea, C. J., Sweeney, T., Callan, J. J., and O’Doherty, J. V. 2008. Animal. 2, 425-434.

O'Shea, C.J., Lynch, M.B., Callan, J.J. and O'Doherty, J.V. 2009. Agriculture, Ecosystems and Environment 131, $154-160$.

Statistical Analysis Systems Institute. 1985. Statistical analysis systems. 6.12, Cary, NC, USA, SAS Institute Inc 